\title{
A vaccine effective against Zika virus is theoretically possible but may not be delivered anytime soon
}

\author{
Andrew W Taylor-Robinson \\ Infectious Diseases Research Group, \\ School of Medical and Applied \\ Sciences, Central Queensland \\ University, Rockhampton, QLD, \\ Australia
}

This article was published in the following Dove Press journal: Research and Reports in Tropical Medicine 5 July 2016

Number of times this article has been viewed

\begin{abstract}
Following the first report in May 2015 of the unexpected emergence of Zika in north east Brazil, there has been an explosive epidemic of this infection across Latin America. The outbreak has caused alarm among social and news media as to the virulence and transmission potential of the Aedes mosquito-borne virus. This debate is heightened by the proximity, both in time and distance, to the forthcoming Olympic Games to be held in Rio de Janeiro this August, provoking fears for the safety of athletes and spectators alike. The threat, real or perceived, is exacerbated by the movement between nations in the same or separate continents of persons who act unwittingly as asymptomatic carriers. Pregnant females are considered at greatest risk because microcephaly in newborn infants is linked to, if not yet proven as caused by, Zika infection. In February this year, the World Health Organization declared that further to the then unconfirmed association between the virus and the clinical manifestations of microcephaly and also Guillain-Barré syndrome, the Zika epidemic was a "public health emergency of international concern". No anti-Zika therapy, vaccine or drug, is currently available and while the production of the former has now been prioritized by multiple funding agencies, the history of infectious disease vaccine development indicates that this may take several years to reach the market place. The fact that Zika is a close relative of yellow fever and Japanese encephalitis viruses, for both of which there are already effective vaccines, provides a rational basis for the fast-tracked laboratory-based preparation of a candidate vaccine. However, undertaking clinical trials on pregnant females provides ethical and practical hurdles to overcome before licensure is granted for public administration. Meanwhile, public health management strategies, including mosquito control programs to reduce breeding, are needed to limit the global spread of this re-emerging disease.
\end{abstract}

Keywords: Zika, flavivirus, epidemic, vaccine

\section{Introduction}

The Aedes mosquito-transmitted viral disease of humans, Zika, was originally identified in 1947 and is named after the rainforest in Uganda, East Africa, where it was first isolated from rhesus macaques. ${ }^{1}$ For close on 70 years, the prevalence of Zika infection was very low, such that prior to now it has attracted little interest apart from arbovirus and tropical medicine specialists. In the last several months, this scenario has changed dramatically, however, subsequent to a major Zika epidemic in over 35 countries in Latin America and the Caribbean. ${ }^{2}$ This includes an estimated 1,400,000 clinical cases in Brazil, from where the outbreak arose in early $2015,{ }^{3}$ although questions regarding the accuracy of reporting have been raised. ${ }^{4}$ Furthermore, the World Health
Correspondence: Andrew W

Taylor-Robinson

School of Medical and Applied Sciences,

Central Queensland University,

Rockhampton, QLD 4702, Australia

Tel +6I 749232008

Email a.taylor-robinson@cqu.edu.au 
Organization (WHO) predicts that by the end of this year up to 4 million people across the Americas may be infected with the Zika virus. ${ }^{5}$ The impact on the vast majority of those people will be minimal, but particularly in infants the effect may be profoundly debilitating and long-lasting. Such is the extent of the issue, real and predicted, and the degree of concern that it has engendered globally, that on February 1, 2016 the International Health Regulations Emergency Committee of the WHO declared the Zika epidemic as "a public health emergency of international concern" and highlighted the importance of aggressive measures to reduce infection, especially of pregnant females and those of childbearing age. ${ }^{6}$ Subsequently, the US Centers for Disease Control and Prevention moved Zika to level 1 activation, ${ }^{7}$ the highest available state of response.

\section{Causative agent of infection and clinical manifestations of disease}

Similar to the etiological agents of yellow fever, Japanese encephalitis and dengue, Zika is a member of the Flavivirus genus of enveloped, positive sense, single-stranded RNA viruses. ${ }^{8}$ Compared to each of these close relatives, infection with which can be severely incapacitating for a person of any age, it is thought that approximately $80 \%$ of adults infected with Zika show no clinical manifestations. ${ }^{9}$ Hence, for several days after being bitten by an infectious mosquito, they may serve as asymptomatic carriers of infection. If a person is ill, the main symptoms may last for up to 1 week and are similar to but less severe than other related febrile illnesses - a mild headache, fever, myalgia, arthralgia, conjunctivitis, and maculopapular rash. ${ }^{10}$ The principal possible consequence of Zika infection, for which there is now claimed to be a causal link, ${ }^{11}$ occurs via congenital transmission from a pregnant female to her fetus in utero or newborn baby, ${ }^{10,12}$ the effects of which can be severe. ${ }^{13}$ In Brazil alone, the virus has been associated with over 4,000 cases of microcephaly, ${ }^{2}$ a previously uncommon condition that as a result of aberrant brain development produces babies with abnormally small heads and, in most cases, neurological impairment. In March 2016, Panama registered a baby born with microcephaly linked to the Zika virus, in what is thought to be the first such case outside Brazil during the current outbreak. The baby died within 4 hours and at postmortem examination the virus envelope protein was detected by enzyme-linked immunosorbent assay in the baby's umbilical cord. ${ }^{14}$ Rarely, Zika is also associated with, but still not proven to be causally linked to, Guillain-Baré syndrome, a neural demyelination syndrome that is considered to be an autoimmune sequela of infectious disease. ${ }^{12,15}$

\section{Global spread and risk to mosquito non-endemic regions}

The Zika epidemic is arousing apprehension among the general public just months before the world's attention will focus on Rio de Janeiro for the summer Olympic Games. At present, the advice to pregnant females from non-endemic regions is to not travel to Brazil and surrounding countries. ${ }^{16}$ Aside from this immediate concern in Latin America, the increasing media frenzy has fed misinformation with regard to the possible global spread of Zika, and the impact this may have on public health in regions that are currently not affected. ${ }^{17}$ As a consequence of global climate change the geographical distribution of $A$. aegypti, the species of mosquito that is considered to act as the principal vector of Zika transmission, is expanding gradually in tropical and subtropical zones. ${ }^{3}$ For non-endemic industrialized nations in North America, Europe, and Australasia, the critical issue is whether or not Zika virus-permissive mosquito populations can adapt for persistence in temperate climates. A more rapid spread of the virus via the intercontinental travel of infected persons is an additional concern, although for Zika to become established in a location distant to an endemic area requires local transmission of the initially imported focus of infection; this is dependent on the availability of the vector. ${ }^{18}$ Vertical, sexual, and blood-borne transmission of Zika has been suggested, ${ }^{19,20}$ which, if confirmed, may provide auxiliary routes to enable viral persistence in regions that are not endemic for Aedes mosquitoes. Thus, one recommendation to prevent disease, especially microcephaly, is to practice safe sex in those territories where Zika is reported as endemic. ${ }^{21}$ Importantly, the risks should be considered in family planning until such time as the apparent association between viral infection and microcephaly is either confirmed or refuted. ${ }^{22,23}$

\section{Another re-emerging infectious disease}

The Zika epidemic comes hard on the heels of other notable infection outbreaks by pathogenic viruses around the world in recent years, each of which has posed a threat to human wellbeing. These include the coronaviruses that cause severe acute respiratory syndrome and Middle East respiratory syndrome, the H1N1 swine influenza, H5N1 and H7N9 avian influenza, and the filovirus Ebola. Each in turn has led epidemiologists to consider transmission cycles and zoonoses, infectious 
disease immunologists to improve emergency measures such as pathogen detection and containment, and vaccinologists to aim to develop effective immunization regimens. ${ }^{24,25}$ In much the same way as the upsurge of Ebola cases in West Africa in 2014, Zika may be considered as a re-emerging infectious disease; that is one which is established but displayed in a novel setting. ${ }^{26}$

\section{Strategies to combat Zika}

While the reasons for the current Zika epidemic in South America are multifactorial, ${ }^{21}$ inadequate vector control of an unexpected population explosion of mosquitoes is a suspected cause. This raises the question as to what guidance is appropriate to provide to combat Zika, especially in industrialized nations where there has been the loudest call for anti-Zika prophylaxis, ${ }^{17}$ such as that which could be provided by sterilizing immunization. In the short term, as anti-viral therapies are yet to be realized alternative means should be used, including low technology measures that focus on vector control such as insecticide fogging, limiting mosquito breeding, and providing protection from mosquito bites. ${ }^{27}$ The delivery of different interventions, singularly or in combination, should be informed by, and thereby tailored to, local settings. What should not be overlooked in the current furore over Zika is that A. aegypti is also responsible for transmitting yellow fever, Japanese encephalitis, dengue, and chikungunya, viruses that have arguably far more impact on global public health. The implementation of any program to limit or eliminate $A$. aegypti as a result of concern over the spread of Zika will have the added benefit of coincidentally reducing the risk of incidence of these other important viral human pathogens. ${ }^{18,28}$ It is also possible that a species of mosquito other than $A$. aegypti is the main vector fueling the current epidemic of Zika in a continent where this virus has not been established previously, although this too would be susceptible to identical means of vector control.

Until now there has been little in the way of research into Zika, both with regard to the virus and the pathologies that it causes. Hence, there is a knowledge gap surrounding infection transmission and clinical manifestations of disease. ${ }^{28}$ Since there has been no pressing demand before the present epidemic, no prophylactic vaccine or therapeutic drug is currently available with which to treat Zika infection. For any infectious disease, the vaccine development pathway from candidate design, via preclinical screening, through Phase I-III clinical trials to final approval for public administration is long, demanding, and expensive. ${ }^{29}$ While this has now been prioritized by international funding agencies for Zika, it may take several years for a vaccine to come to commercial fruition.

\section{Vaccine development pathway}

As efficacious vaccines have been prepared against yellow fever and Japanese encephalitis viruses, it is anticipated that a similar therapeutic is feasible for Zika. ${ }^{30}$ Nevertheless, in spite of ring-fenced funds to support research into developing a vaccine, ${ }^{31}$ a note of caution should be advised. It is feasible that the laboratory-based design and preclinical screening of a candidate vaccine may be fast-tracked in a matter of months, perhaps by the end of $2016 .^{32}$ This is particularly so if a DNA-based construct is developed. ${ }^{30}$ Both the Indian pharmaceutical company Bharat Biotech and the US National Institute of Allergy and Infectious Diseases have plans to produce a vaccine. ${ }^{32}$ However, in all probability, it will take several years to perform any ensuing clinical trials and to attain full approval from national regulatory bodies for public administration. ${ }^{21,33}$ Although to gain ethical approval for, and to conduct, tests of vaccine safety and efficacy in humans necessitates diligence and caution at all times, the due process for any candidate vaccine that is dispensed to pregnant females is naturally subject to extremely exacting analysis. ${ }^{34,35}$ This would relate especially to Zika as, allegedly, the gravest manifestation of infection, microcephaly, affects pregnancy.

The positive news is that the latest clinical trial of an experimental dengue vaccine, TV003, has proved 100\% effective, albeit a small scale volunteer challenge study of only the dengue- 2 serotype performed under highly controlled conditions. ${ }^{36}$ While this is no doubt a significant breakthrough in the ongoing fight against dengue, as an offshoot of this success it is hoped that a modified version of the live attenuated construct may be developed in order to treat the related Zika virus. This head start may accelerate production of a candidate Zika vaccine but will not truncate its potentially arduous journey through clinical trials. During this time, scientists, clinicians, and health care professionals all should be attentive to stress the standard caveats and qualifications to the outcomes of any study, so not to augment the plethora of misinformation that concerns Zika by implying, however unintentionally, that a vaccine is forthcoming anytime soon. ${ }^{17,31}$

\section{Conclusion}

The recent striking emergence of cases of Zika in Latin America poses a threat for a worldwide outbreak of this mosquito-borne flavivirus infection. The public health challenges presented by Zika will remain unless and until the 
current deficit of knowledge relating to its epidemiology, pathology, and immunology is addressed. Current measures to combat the spread of infection rely on vector control programs, which evidently require improved operation and integrated management. A specific anti-Zika therapy does not exist, but in response to the ongoing epidemic research funds have been committed to develop a vaccine. While prior success in producing effective vaccines against closely related human viral pathogens provides a proof of principle for this approach, vaccine design and clinical testing can be laborious and the timescale long. In the short term, therefore, optimism regarding delivery of a Zika vaccine should be tempered by realism regarding a delivery date.

\section{Disclosure}

The author reports no conflicts of interest in this work.

\section{References}

1. Dick GW, Kitchen SF, Haddow AJ. Zika virus. I. Isolations and serological specificity. Trans R Soc Trop Med Hyg. 1952;46(5):509-520.

2. Fauci AS, Morens DM. Zika Virus in the Americas - Yet Another Arbovirus Threat. N Engl J Med. 2016;374(7):601-604.

3. Pan American Health Organization. Zika virus infection. Washington DC: PAHO/WHO; 2016. Available from: http://www.paho.org/hq/index. php?option $=$ com_content $\&$ view $=$ article $\&$ id $=11585 \&$ Itemid $=41688 \&$ lang=en. Accessed May 25, 2016.

4. Samarasekera U, Triunfol M. Concern over Zika virus grips the world. Lancet. 2016;387(10018):521-524.

5. Zika virus: up to four million Zika cases predicted [webpage on the Internet]. BBC News; 2016 [cited January 28, 2016]. Available from: http://www.bbc.com/news/health-35427493. Accessed May 25, 2016.

6. who.int [homepage on the Internet]. WHO Director-General summarizes the outcome of the Emergency Committee regarding clusters of microcephaly and Guillain-Barré syndrome. World Health Organization; 2016. Available from: http://who.int/mediacentre/news/statements/2016/ emergency-committee-zika-microcephaly/en/. Accessed May 25, 2016.

7. cdc.gov [homepage on the Internet]. Zika virus, what CDC is doing? Centers for Disease Control and Prevention; 2016. Available from: http://www.cdc.gov/zika/cdc-role.html. Accessed May 25, 2016.

8. Kuno G, Chang GJ. Full-length sequencing and genomic characterization of Bagaza, Kedougou, and Zika viruses. Arch Virol. 2007;152(4): 687-696.

9. Ginier M, Neumayr A, Günther S, Schmidt-Chanasit J, Blum J. Zika without symptoms in returning travellers: What are the implications? Travel Med Infect Dis. 2016;14(1):16-20.

10. cdc.gov [homepage on the Internet]. Zika virus - symptoms, diagnosis $\&$ treatment. Centers for Disease Control and Prevention; 2016 [cited February 3, 2016]. Available from: http://www.cdc.gov/zika/symptoms/. Accessed May 25, 2016.

11. Rasmussen SA, Jamieson DJ, Honein MA, Petersen LR. Zika Virus and Birth Defects--Reviewing the Evidence for Causality. $N$ Engl J Med. 2016;374(20):1981-1987.

12. European Centre for Disease Prevention and Control. Rapid RiskAssessment. Zika virus epidemic: potential association with microcephaly and Guillain-Barré syndrome. Stockholm: ECDC; 2015. Available from: http://ecdc. europa.eu/en/publications/Publications/zika-virusamericas-association-with-microcephaly-rapid-risk-assessment.pdf. Accessed May 25, 2016.
13. Meaney-Delman D, Rasmussen SA, Staples JE, et al. Zika Virus and Pregnancy: What Obstetric Health Care Providers Need To Know. Obstet Gynecol. 2016;127(4):642-648.

14. Zika: Panama has 'first microcephaly case outside Brazil' [webpage on the Internet]. BBC News; 2016 [cited March 19, 2016]. Available from: http://www.bbc.com/news/world-latin-america-35850696. Accessed May 25, 2016.

15. Cao-Lormeau VM, Roche C, Teissier A, et al. Zika virus, French polynesia, South pacific, 2013. Emerg Infect Dis. 2014;20(6):1085-1086.

16. U.S. National Library of Medicine [homepage on the Internet]. CDC broadens Zika virus travel alert for pregnant women; 2016 [cited January 27, 2016]. Available from: https://www.nlm.nih.gov/medlineplus/ news/fullstory_156896.html. Accessed May 25, 2016.

17. Zika virus: rumours and theories fuel 'information war' [webpage on the Internet]. BBC News; 2016 [cited February 18, 2016]. Available from: http://www.bbc.com/news/world-latin-america-35601808. Accessed May 25, 2016.

18. Gyawali N, Bradbury RS, Taylor-Robinson AW. The global spread of Zika virus: is public and media concern justified in regions currently unaffected? Infect Dis Poverty. 2016;5:37.

19. Foy BD, Kobylinski KC, Chilson Foy JL, et al. Probable non-vector-borne transmission of Zika virus, Colorado, USA. Emerg Infect Dis. 2011;17(5): $880-882$.

20. Musso D, Roche C, Robin E, et al. Potential sexual transmission of Zika virus. Emerg Infect Dis. 2015;21(2):359-361.

21. sciencemag.org [homepage on the Internet]. Zika virus: your questions answered. [cited January 29, 2016]. Available from: http://www. sciencemag.org/news/2016/01/zika-virus-your-questions-answered. Accessed May 25, 2016.

22. Schuler-Faccini L, Ribeiro EM, Feitosa IM, et al. Possible Association Between Zika Virus Infection and Microcephaly - Brazil, 2015. MMWR Morb Mortal Wkly Rep. 2016;65(3):59-62.

23. Calvet G, Aguiar RS, Melo AS, et al. Detection and sequencing of Zika virus from amniotic fluid of fetuses with microcephaly in Brazil: a case study. Lancet Infect Dis. Epub 2016 February 17.

24. García-Sastre A, Mena I. Novel vaccine strategies against emerging viruses. Curr Opin Virol. 2013;3(2):210-216.

25. Liang L, Felgner PL. A systems biology approach for diagnostic and vaccine antigen discovery in tropical infectious diseases. Curr Opin Infect Dis. 2015;28(5):438-445.

26. Carroll MW, Matthews DA, Hiscox JA, et al. Temporal and spatial analysis of the 2014-2015 Ebola virus outbreak in West Africa. Nature. 2015;524(7563):97-101.

27. Becker N, Petrić D, Zgomba M, et al. Mosquitoes and their control. Berlin: Springer; 2010.

28. Taylor-Robinson AW. Local transmission of Zika virus infection is possible in Australia but should be contained by current vector control measures. Infectious Diseases and Vaccines: Open Access. 2016;1:001.

29. Kochhar S, Rath B, Seeber LD, et al. Introducing new vaccines in developing countries. Expert Rev Vaccines. 2013;12(12):1465-1478.

30. Ishikawa T, Yamanaka A, Konishi E. A review of successful flavivirus vaccines and the problems with those flaviviruses for which vaccines are not yet available. Vaccine. 2014;32(12):1326-1337.

31. Obama to seek $\$ 1.8 \mathrm{bn}$ from Congress to combat Zika virus [webpage on the Internet]. The Guardian; 2016 [cited February 9, 2016]. Available from: http://www.theguardian.com/us-news/2016/feb/08/obama-zikavirus-congress-research-funding-vaccine. Accessed May 25, 2016.

32. Zika vaccine possible 'within months' [webpage on the Internet]. BBC News; 2016 [cited March 4, 2016]. Available from: http://www.bbc. com/news/health-35727047. Accessed May 25, 2016.

33. theconversation.com [homepage on the Internet]. Here's why we don't have a vaccine for Zika (and other mosquito-borne viruses). [cited February 2, 2016]. Available from: https:// theconversation.com/ heres-why-we-dont-have-a-vaccine-for-zika-and-other-mosquito-borneviruses-53871. Accessed May 25, 2016. 
34. Omer SB, Beigi RH. Pregnancy in the Time of Zika: Addressing Barriers for Developing Vaccines and Other Measures for Pregnant Women JAMA. 2016;315(12):1227-1228.

35. Iacobucci G. Zika highlights need for ethical framework for developing vaccines for pregnant women. BMJ. 2016;352:11155.
36. nature.com [homepage on the Internet]. Dengue vaccine aces trailblazing trial. Protection against virus raises hopes of vaccine development for dengue and even Zika. [cited March 16, 2016]. Available from: http:// www.nature.com/news/dengue-vaccine-aces-trailblazing-trial-1.19576. Accessed May 25, 2016.

\section{Publish your work in this journal}

Research and Reports in Tropical Medicine is an international, peerreviewed, open access journal publishing original research, case reports, editorials, reviews and commentaries on all areas of tropical medicine, including: Diseases and medicine in tropical regions; Entomology; Epidemiology; Health economics issues; Infectious disease; Laboratory science and new technology in tropical medicine; Parasitology; Public health medicine/health care policy in tropical regions; and Microbiology.

The manuscript management system is completely online and includes a very quick and fair peer-review system. Visit http://www.dovepress. com/testimonials.php to read real quotes from published authors.

Submit your manuscript here: https://www.dovepress.com/research-and-reports-in-tropical-medicine-journal 